\title{
The Biochemical Mode of Action of the Sulphonamide Drugs*
}

\author{
By D. D. WOODS \\ Microbiology Unit, Department of Biochemistry, University of Oxford
}

(Received 23 March 1962)

It is the first occasion in this series of lectures in which the major part of the problem under discussion concerns the work of the lecturer himself. This is rather like entering the confessional in public, and you will forgive me, I know, for having provided myself with a few lantern slides in order to darken the room from time to time. A difficulty that became very real to me in preparing this lecture was to recall my actual processes of thought at the time of this work 21 years ago. So much has happened since which has a direct bearing on it that it is extremely difficult to cast out things which have since become, so to speak, part of my phenotypic constitution. However, I will try to be strictly honest and if things in fact did not occur in the way in which, in the light of the present knowledge, they ought to have occurred, this is not my fault. I am instructed to discuss the interplay of theory, experiment, models and chance in my work; this means that I really have to be frank!

It is clearly impossible for me to describe my own experiences during the period at issue without telling you something of my own background at the time. The story begins with a very large slice of chance. The problem to be discussed is essentially one of chemical microbiology. I became interested in this subject at $8.30 \mathrm{p.m}$. on Friday 9 May 1930. At that time the late Dr Marjory Stephenson (a portrait appeared in this Journal (1949) 3, facing p. 329) gave a broadcast talk in a series entitled 'Biochemistry: what it is and what it does'. Her particular topic was 'How microbes live or Some aspects of bacterial physiology'. This short talk made a deep impression upon me; I was $\mathbf{1 8}$ at the time, which is no doubt an impressionable age. I would like to quote two short passages from it. (I hasten to add this is not due to a phenomenal feat of memory on my part, but to the courtesy and industry of the British Broadcasting Corporation, who after a lapse of nearly 31 years, managed to provide me with a copy of her actual script.) In the course of this broadcast she said:

The problem of growth lies at the very heart of biochemistry. The biochemist follows the scriptural advice 'consider the lilies how they grow', but all forms of life are lilies to us; when we know how the microbe grows we shall be a long way towards knowing how lilies and lambs grow.

In other words, by studying microbes I would not only learn something of their biochemistry but also of that of all living organisms. This point of view has been amply borne out during the past three decades. Her concluding sentence was:

I don't know whether I have persuaded any patient listener to think that microbes are an interesting study on their own account, but I can assure you that those of us who spend

* A lecture delivered in the University of Oxford on 17 May 1961 in a series entitled 'Case histories in biological discovery' organized by Dr A. C. Crombie, University Lecturer in the History of Science. 
our time trying to persuade these little people to disclose their secrets, find our lives full of interest and often of excitement.

Well, she had at least one convert, for since that broadcast the whole of my scientific life has been devoted either to preparing myself for, or actually studying, the biochemistry of micro-organisms.

At that time I was in my last year at school and waiting to go up to Cambridge. But in the University of Cambridge was the world-famed School of Biochemistry led and inspired by Gowland Hopkins, and within the Department of Biochemistry worked Dr Marjory Stephenson. So my dreams had perhaps some small hope of materializing. I decided when I went to Cambridge to abandon certain physical sciences, retaining chemistry, but switching over to Botany and Zoology as the other subjects for Part I of the Tripos. Eventually I was able to take up Biochemistry itself for my Part II. When finally the news arrived that I had done well enough to attract a D.S.I.R. grant to stay on and do research I ran straight to Marjory Stephenson who was kind enough to take me on as a Ph.D. student. So you see that my presence here today lecturing on this subject owes much to chance, perhaps fortified by a rather one-track mind.

I spent 6 happy years researching under Marjory Stephenson on problems of bacterial metabolism in a Department which had a very lively atmosphere and where much work on enzymes was in progress and I became fairly knowledgeable, I think, about the dynamic aspects of biochemistry as a whole. In the nineteen-thirties there were two main schools of bacterial chemistry in this country. One led by Marjory Stephenson was mainly concerned with the metabolic aspects, that is the chemical changes induced by bacteria in their environment. The other led by Dr (now Sir Paul) Fildes (a portrait appeared in this Journal (1962) 27, facing p. 335), now happily here with us in alleged retirement in Oxford, studied the nutritional requirements of bacteria, and in particular those vitamin-like substances, which albeit in very low concentrations, were essential for the growth of many bacteria. As we now know many of these have turned out to be precursors of coenzymes or part of the structure of enzymes catalysing key metabolic processes of the cell. Furthermore, the Fildes' school used in their work mainly bacteria of medical interest, whilst we in Cambridge had been concerned with non-pathogens, which are equally important and in nature far greater numerically.

In 1939 Fildes offered me a fellowship to join his team. I accepted this with alacrity not only because it offered an opportunity to extend my experience into the other main current field of bacterial chemistry, but because it had always been Marjory Stephenson's philosophy that problems in our field would be most likely to be solved if attacked at all levels of investigation, which meant of course the nutritional and more biological approaches as well as the more purely metabolic one I had used so far. I joined the Fildes' Unit on the rather inappropriate date of 1 April 1939. I worked for a few months without much success on the nutrition of the gonococcus, an organism which had been shown to require charcoal for best growth. Then we turned to sulphonamides. To recapitulate my own experience up till that time, I was fairly saturated with regard to enzyme and metabolic biochemistry and I was now working in a more biological environment which was also well provided with the know-how of bacterial vitamins. 


\section{The sulphonamides: historical background}

I have time only briefly to sketch the earlier history of the sulphonamides. As long ago as 1885 Paul Ehrlich proposed his view that the organism contained specific receptors which fixed essential foodstuffs, and that toxic drugs might act by fixing themselves to these receptors because of chemical similarity to the foodstuff in question. Amongst such toxic agents were dyestuffs (vital stains) which could clearly be envisaged as becoming fixed by the protoplasm. There was a good deal of work on the bactericidal action of dyestuffs during the first 15 years of this century, notably by Churchman and by Simon \& Wood; however, no useful thera-

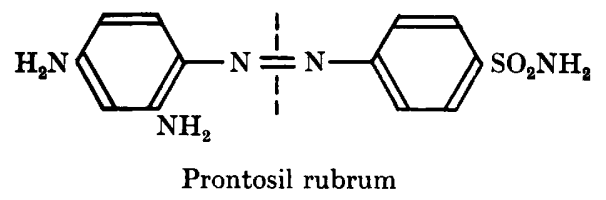

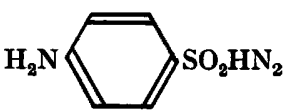

Sulphanilamide<smiles>Nc1ccc(S(=O)(=O)NC2=NCCS2)cc1</smiles>

Sulphathiazole ( $\mathrm{M}$ and $\mathrm{B}$ 760)
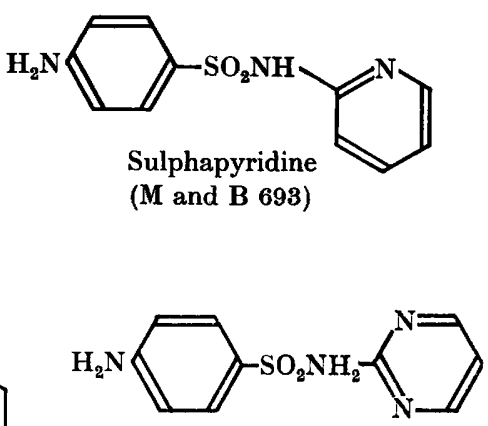

Sulphadiazine

Fig. 1. Structural formulae of prontosil rubrum and some sulphonamides.

peutic agents emerged. The major step forward was that of Domagk (1935). He was working in the laboratories of I. G. Farbenindustrie where there had been earlier work on the antibacterial action of azo dyes. Domagk found that azo compounds containing a sulphonamide residue had slight activity against streptococcal infections in mice. Following up this clue he showed that a red dye, prontosil rubrum (Fig. 1) had powerful curative effects on streptococcal infections in mice and clinical trials showed it to be highly effective against puerperal fever in humans.

But Domagk had also found that prontosil, although active in vivo, had no inhibitory action on the growth of bacteria on culture media in the laboratory. Workers at the Pasteur Institute (Tréfouël, Tréfouël, Nitti \& Bovet, 1935) suggested that prontosil was broken down in the animal body, yielding sulphanilamide (Fig. 1) and showed that the latter was active in laboratory cultures. Fuller (1937) finally confirmed that prontosil was indeed broken down in vivo to sulphanilamide.

Sulphanilamide led to the discovery of more potent antibacterial chemotherapeutic agents. The molecule was modified chemically by traditional methods, parti- 
cularly by workers at May and Baker Ltd. under Dr A. J. Ewins. The most active drugs were those in which a basic substituent was introduced into the amide group producing compounds (Fig. 1) such as sulphapyridine ( $M$ and B 693), sulphathiazole (M and $B$ 760), sulphadiazine and so on. Such drugs were being tested by Whitby and his colleagues at the Middlesex Hospital in 1938/9.

\section{Biological activity of sulphonamides: anti-sulphonamide agents}

It is perhaps a cliché, though nevertheless in my opinion profoundly true, that biochemical discoveries spring in the main from biological observations. Let us first examine what knowledge had accumulated by the late nineteen-thirties

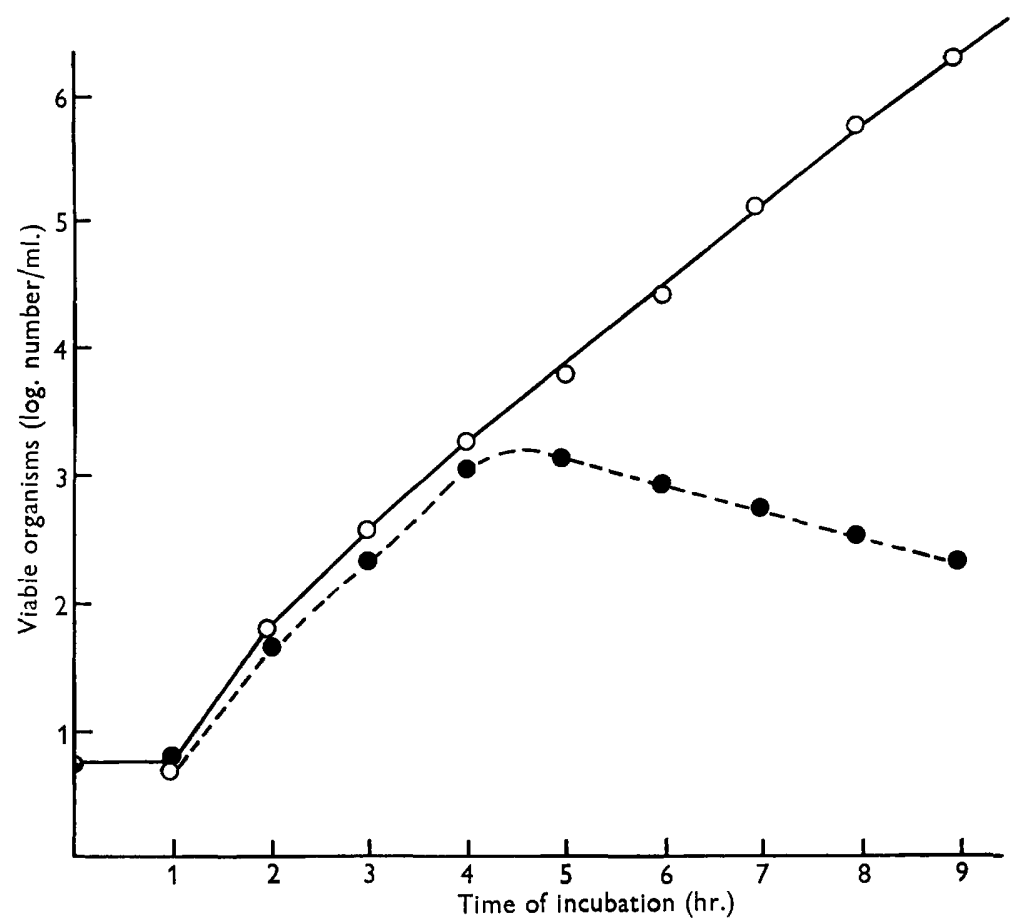

Fig. 2. Early growth of haemolytic streptococci in blood broth without $(-\mathrm{O}-$ ) and with (- - ) sulphanilamide $(10 \mu \mathrm{M})$.

regarding the biological nature of sulphonamide action. First, the sulphonamides appeared to be primarily bacteriostatic; they did not kill the bacteria, and living organisms could always be obtained from cultures treated with sulphonamides. A proportion of organisms, however, probably died in artificial culture media when they were prevented from dividing. The evidence was therefore that sulphonamides were not general cell poisons. Secondly, in complex media such as blood broth the organisms underwent a number of divisions in a perfectly normal manner before the effect of sulphonamide became manifest (Fig. 2). The length of this initial period of normal growth depended on the complexity of the medium used, being longest in very complex media (such as the blood broth illustrated). It occurred, however, even if only to the extent of one or two generations, in the simplest medium sup- 
porting the growth of the test organism. Thirdly, sulphonamides were relatively ineffective clinically in open wounds where there was considerable pus.

One interpretation of these observations was that material derived from natural sources (such as peptone, blood, etc.) contains substances which in some way prevent the action of the sulphonamides, and furthermore that the bacteria of the inoculum may also contain such substances. Only when they are used up do the sulphonamides act. Early in 1939 McIntosh \& Whitby of the Bland-Sutton Institute of the Middlesex Hospital (which also housed the Fildes' Unit) examined and rejected experimentally a number of possibilities for sulphonamide action and by a process of exclusion suggested that they probably act ' by neutralization of some metabolic function or enzymatic activity'. This hypothesis was certainly inspired by informal tea-time discussions with Fildes and his colleagues whose work on growth factor requirements had by then led them to think in terms of essential metabolites, that is vitamin-like substances essential for normal growth and which are synthesized by many bacteria for themselves; they become growth factors for species which cannot achieve their synthesis. In more modern terms of Ehrlich's concepts drugs (including sulphonamides) might act by interfering with the normal function of such essential metabolites.

Clearly, however, whatever the hypothesis, anything that could be found out about the nature of anti-sulphonamide substances present in micro-organisms themselves might throw light on the mechanism of sulphonamide action. This conclusion was apparently reached by several workers more or less simultaneously. Just before our own intensive work on the subject, Stamp (1939) succeeded in extracting from a haemolytic streptococcus material with anti-sulphonamide activity. He did not (with Beall) establish its chemical nature, probably because chemical analysis was attempted at too early a stage of purification. He concluded it was a mixture of substances of relatively low molecular weight. He also suggested that the substance or substances might contain a necessary nutritive factor or coenzyme the production or activity of which is interfered with by the drug. Concurrently with our own work Green (1940) in Sheffield obtained from Brucella abortus a partly purified fraction which overcame sulphonamide inhibition of the growth of the same and other organisms; it also greatly stimulated growth. No conclusions were reached at the time about the chemical nature.

This problem was clearly tailor-made for the Fildes' Unit with their wide experience of the detection and isolation of vitamin-like substances for bacteria. Indeed they had recently found glutamine to be an essential growth factor for Streptococcus and in view of the fact that both it and sulphanilamide were amides, had tested whether glutamine might have anti-sulphonamide activity. The results were however negative.

From previous experience the Fildes' group (which I had now joined) took the view that a substance of importance to key metabolic processes in one organism was likely also to be essential to other organisms, and to be of wide distribution. Furthermore, it was by then known that sulphonamides under appropriate conditions inhibited the growth of a fairly wide variety of bacteria. We therefore decided to look for anti-sulphonamide factors in yeast-an organism which had proved in the past a good source of vitamins both for man and bacteria. Since the resources of the Unit were slender for the large scale cultivation of bacteria there was the added 
advantage that yeast could be bought by the pound in the baker's shop or begged from the nearest brewery. About the middle of July 1939, Fildes prepared a weakly alkaline extract of yeast (as recommended by Stamp for his streptococcal extracts); it had high anti-sulphonamide activity with the test organism, which was a virulent strain of Streptococcus haemolyticus. From then on I took over the work since it was likely to be predominantly biochemical in character.

Before dealing further with technical matters I should like briefly to recall to you the general situation at the time. At the end of July 1939 war appeared to be unavoidable and imminent. Large-scale bombing of cities was expected with consequent high incidence of dirty wounds, delay in the treatment of them and consequent risk of more general infection. At that time, before the birth of penicillin, the sulphonamides were the only successful agents for chemotherapy of bacterial infections. Anything we could do to discover their mode of action might conceivably help us to design other chemotherapeutic agents. The time seemed to be one for urgent work at the bench, rather than for preparing oneself intellectually to attack the problem. I was singularly ignorant of the science of pharmacology, so clearly important for this work, and I had certainly not read all the original work of Ehrlich and other pioneers of chemotherapy. But I was working in an environment experienced in the isolation and study of bacterial growth factors; furthermore, in the laboratory next door Whitby and his colleagues were controlling the clinical tests of the latest sulphonamide products of May \& Baker and this provided a sense of reality.

\section{Discovery of the anti-sulphonamide activity of $\mathrm{p}$-aminobenzoic acid}

It will be clear to you by now that the experimental work on the anti-sulphonamide factor or factors present in yeast was started with the tentative working hypothesis that such a factor might be akin to a bacterial growth factor or vitamin. The technology employed was therefore in general that of research on vitamins. The biological test was fortunately a simple one. The test organism, a virulent strain of Streptococcus haemolyticus, was grown on the simplest medium then known to support its growth. This was in fact rather complex and contained peptone, glucose and a number of vitamins known to be essential. To prevent carry-over of antisulphonamides the inoculum used was small (about 100 organisms/ml.) Almost full growth was attained in $24 \mathrm{hr}$. Sufficient sulphanilamide (about $\mathrm{m} / \mathbf{3 0 0 0}$ ) was added completely to prevent growth for at least 5 days. The yeast extract (or fractions derived from it) was added at falling concentrations each decreasing by a factor of 5 . The result of the titration was judged simply by holding the tubes before the window and deciding by visual inspection whether growth had occurred or not. The lowest concentration of the test material giving growth in the presence of sulphonamide before 5 days was considered to be the end point of the titration. I know that in modern terms this technique seems horribly crude, but I do not think any more elaborate method of assessment, such as viable counts or quantitative measurement of turbidity, would have given any more information and would certainly have consumed much more time. I must, however, confess to one stupidity in these tests. The first time I did one the final volume of the medium was in fact $11 \mathrm{ml}$. instead of the $10 \mathrm{ml}$. intended. I failed to realize this until almost the end of the work; consequently my concentrations of sulphonamide and other test substances 
were all curious values such as $\mathbf{m} / 1100$ instead of more usual and sensible $\mathrm{m} / \mathbf{1 0 0 0}$. I can offer no excuse for this lapse.

Two lines of experimental approach were carried out concurrently (Fig. 3). The more biological and kinetic aspects of the anti-sulphonamide action of yeast extracts were examined with relatively crude extracts, and the apparently more important observations repeated with more purified material as it became available. I will return later to this aspect of the work, but it is important for the ultimate results to realize that it neither preceded nor succeeded that about to be described.

The other approach (Fig. 3) was a straightforward attempt to concentrate, purify and isolate the factor itself and establish its chemical nature. It was hoped of course that from the behaviour with the reagents used it would be possible to learn something about the chemical nature of the substance. Furthermore, it was a deliberate policy, before any actual isolation, to try to identify by specific tests some of the chemical groupings in the molecule. I will not attempt any full description of this

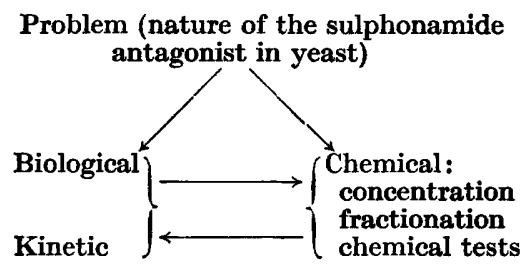

Fig. 3.

search but simply summarize the significant findings. My own first experiment with yeast extract was on 8 August 1939. The methods used were those traditionally associated at the time with the isolation of substances from natural sources. Procedures, for example, such as precipitation of the factor or inactive contaminants with ethanol, acetone and heavy metals, and extraction with a variety of solvents at different $\mathrm{pH}$ values. Suffice it to say that some degree of purification was achieved with relatively little loss of the original activity and that the behaviour during fractionation suggested that I was dealing with a single substance (or group of chemically related substances).

One of the main difficulties at the time was the lack of facilities we had for really large scale work, particularly in the first stages of the extraction. To quote one perhaps less serious example, our cold room accommodation consisted only of a domestic type of refrigerator while I frequently had several litres of fluid to store overnight. Eventually I was able to find space for it in the hospital mortuary, hidden away along gloomy corridors in the basement. So my days for several months started and ended with a visit to this cheerless place to rescue or deposit my concentrates from among the white-sheeted figures. So now you know what 'stored in the cold room' may sometimes mean.

Apart from such impediments it is interesting, though perhaps idle, to speculate how much easier the whole thing would have been had modern techniques such as paper chromatography then been available. A few runs on paper with various solvents; detection of the active spots by laying the developed chromatogram on medium containing sulphonamide and seeded with the test organism: we might easily have obtained almost pure material in a few weeks. 
However, my material then, though still very crude, seemed sufficiently purified to make it worth while to attempt a few chemical tests. The fact that it was extracted by ether from weakly acid solutions, though not from alkaline, suggested it might be itself a weak acid, perhaps, since it was a natural product, a carboxylic acid. The acidic nature was confirmed by the fact that esterification of the extract with ethanol led to complete loss of activity which was, however, regained when the treated material was hydrolysed:

$$
R . \mathrm{COOH}+\mathrm{C}_{2} \mathrm{H}_{5} \mathrm{OH} \rightleftharpoons R . \mathrm{COOC}_{2} \mathrm{H}_{5}+\mathrm{H}_{2} \mathrm{O} .
$$

I also sought evidence as to whether amino groups were present; mild treatment with nitrous acid destroyed all anti-sulphonamide activity, thus suggesting this was possible. Acetylation of the extract with acetic anhydride in pyridine led to complete loss of activity which was regained on hydrolysis:

$$
R . \mathrm{NH}_{2}+\mathrm{CH}_{3} \mathrm{COOH} \rightleftharpoons R \text {. NH. OC. } \mathrm{CH}_{3} \text {. }
$$

The material with anti-sulphonamide activity appeared to have both basic and acidic groups. Yet ordinary amino acids were apparently excluded by the fact that the active material was soluble in ether. The most purified material I then had gave a red colour when diazotized and coupled with a naphthylamine derivative. This indicated the presence of an aromatic amino group, though it certainly did not prove that the actual active substance contained such a grouping-merely that it was present in the concentrate, perhaps in the active substance, perhaps only in an impurity.

To summarize then, the evidence indicated at least the possibility that the antisulphonamide contained $(a)$ a benzene or other aromatic nucleus, $(b)$ an amino group and $(c)$ a weakly acidic group, possibly a carboxylic group. These chemical properties were also to be observed in sulphanilamide itself (Fig. 1), since it also contains a diazotizable aromatic amino group and the other substituent on the benzene ring (the sulphonamide group, $-\mathrm{SO}_{2} \mathrm{NH}_{2}$ ) is weakly acidic. I would emphasize that these indications of the possible chemical structure had been deduced not from the properties of an isolated pure substance but from tests with relatively crude material and from the association of biological activity with various chemical properties. It does perhaps illustrate the value of such a combined approach. But clearly the conclusions were only tentative.

I must return now to the more biological and kinetic studies which had been proceeding concurrently, and I will mention only the relevant observations. First, although the initial yeast extracts increased the rate of growth of the test organism on the basal medium, this effect disappeared early during purification, leaving only the anti-sulphonamide action. Such action could not therefore be due to nonspecific growth stimulation by the yeast extract. Secondly, quantitative considerations of the relation between dry weight of even the crude extracts and the amount of sulphonamide whose inhibitory action was overcome made it clear that one molecule of the active substance must be antagonizing the action of many molecules of sulphanilamide. Thus it was unlikely that the antagonist was inactivating the sulphonamide by combining with it in some way. Finally, and most important, there was a rather strict quantitative relationship between the concentration of the drug and the amount of yeast extract required to overcome its action. If the drug 
were increased 5- or $\mathbf{2 5}$-fold then the amount of yeast extract required to restore growth was similarly increased.

Taking together the main results of the two methods of approach (Fig. 3) there was evidence that the antagonist might be similar in chemical structure to sulphanilamide itself and that there was a strict quantitative relationship between the two in controlling growth. To me, with the background of my training in Cambridge, this situation was clearly reminiscent of the phenomenon of competitive inhibition of enzyme reactions by substances analogous to the substrate. This phenomenon had first been discovered by Quastel \& Wooldridge (1928) in Hopkins's laboratory for the succinic dehydrogenase of Escherichia coli. This enzyme, which catalyses the oxidation of succinate to fumarate in the presence of a hydrogen acceptor, was competitively inhibited by malonate, which is the analogue of succinate with one less $\mathrm{CH}_{2}$ group (Fig. 4); when malonate concentration is increased, the inhibition of enzyme activity can be overcome by increasing the concentration of succinate to a similar extent. In the present case one would have to suppose the yeast factor to be the substrate of a bacterial enzyme and sulphanilamide the analogue which competitively inhibits the activity of the enzyme.

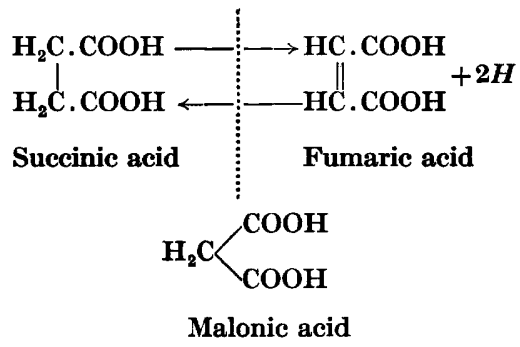

Fig. 4. Competitive inhibition of succinic dehydrogenase.

I was encouraged by this reasoning to try a few shots in the dark and to test for anti-sulphonamide activity some compounds which were both similar in structure to sulphanilamide and compatible with the sort of chemistry deduced for the yeast extract factor. One compound was, from what I have said earlier, an obvious candidate for the first test. It was $p$-aminobenzoic acid and was fortunately obtainable at small cost from the British Drug Houses Ltd.; the test was put up at 1 p.m. on 14 December 1939 and I must admit that 12.30 p.m. on 15 December, when I took the tubes out of the incubator, was (and still is) the most exciting moment in my scientific life. The photograph (Pl. 1, fig. 1) of a recent repetition of the important parts of this experiment perhaps also illustrates the simplicity of the test procedure. A different organism had to be used since the original was no longer available and to make things fairer I asked my colleague $\mathrm{Dr}$ J. G. Morris to put up the test; at any rate it shows that the critical findings can still be repeated. There are controls on the basal medium without (tube 1) and with (tube 2) sulphanilamide showing growth and no growth respectively. A control with $p$-aminobenzoic acid only (tube 5) shows that it does not itself inhibit growth. Finally, tubes ( 3 and 4 ) to which both sulphonamide and $p$-aminobenzoic acid have been added show that the inhibitory effect of the former has been overcome. A repeat of the original experiment was in the incubator by 3.45 p.m. on the same day; how- 
ever, all was well and the $p$-aminobenzoic acid was so active that it took me two further tests to reach the end point of the titration.

As with the yeast extract there was a clear-cut competitive and quantitative relationship between the concentration of sulphanilamide and the concentration of $p$-aminobenzoic acid required to overcome its inhibition. (This is illustrated for another organism in Fig. 8.) One molecule of $p$-aminobenzoic acid antagonized the action of about $10^{4}$ molecules of sulphanilamide. It was highly specific in its action; the ortho and meta isomers were inactive, and any weak activity of related substances was probably explained by their conversion to $p$-aminobenzoic acid itself or by the presence of the latter as an impurity.

There was thus strong evidence from the close correspondence of biological and chemical properties that the active factor in yeast extract was $p$-aminobenzoic acid though in the absence of actual isolation this was not certain; it might have been a closely related compound, though none available for test had comparable activity.

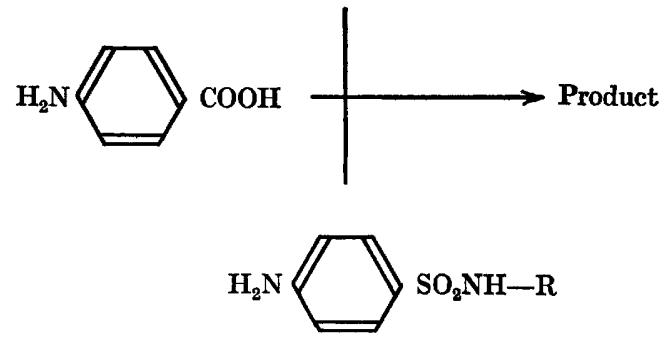

Fig. 5. Competitive inhibition of the utilization of $p$-aminobenzoic acid by sulphonamides.

\section{The hypothesis}

In the light of these results I put forward a working hypothesis for the biochemical mode of action of the sulphonamides (Woods, 1940). In its simplest terms this suggested that $p$-aminobenzoic acid was a substance essential for the growth of bacteria, but was normally synthesized by them for themselves; it belonged to the class which Fildes had christened essential metabolites. It was further suggested that the sulphonamides, by virtue of their similarity in chemical structure to $p$-aminobenzoic acid, competitively inhibit the enzyme reaction by which the latter is further utilized by the organism (Fig. 5). In enzymological terms the sulphonamide was envisaged as competing with $p$-aminobenzoic acid for combination with the active centres of the enzymes concerned.

My brief for this lecture says that I should assess the role played by models in the work. I have to confess that in framing this hypothesis originally I did not build molecular models of the substances in question, but relied only in a simple-minded way on one-dimensional geographical chemistry, that is on the structural formulae as you see them in Fig. 5. However, the resemblance in molecular architecture between $p$-aminobenzoic acid and sulphanilamide may be seen in the photographs of the molecular modes (Pl. 1, fig. 2). Of course it is not only the spatial distances between polar groups which may combine with the enzyme that matters, but also the charge on such groups.

This work and the inferences drawn from it was first reported at a meeting of the 
Biochemical Society on Saturday 17 February 1940 in Sheffield (Woods \& Fildes, 1940). It was the most interesting piece of work in which I have been concerned and certainly the most rapid. In retrospect it scarcely seems possible that it all happened in just over 6 months; we must have had a lot of luck.

I worked on for some time examining the specificity of the $p$-aminobenzoic acid/ sulphonamide relationship and found it to hold with every sulphonamide drug and with every organism I tested. I also continued attempts to isolate the material from yeast in pure, crystalline form but did not get beyond about a few milligrams of about $50 \%$ pure product. By the next summer I had been removed to other activities more directly concerned with the war and was able to take no further part, greatly to my regret, in the immediate development of the work and the further testing of the hypothesis.

\section{Confirmation of the hypothesis}

I should like, however, to give some brief consideration to the extent to which the hypothesis has been confirmed. It predicted that $p$-aminobenzoic acid was a key substance in bacterial metabolism, that it was in fact an essential metabolite. At the time it was not known to be a growth factor for any organism, nor was it even known to be of biological occurrence. The best confirmation the hypothesis could receive was therefore an observation that $p$-aminobenzoic acid was an essential growth factor for some bacterium. This was not long in coming. Rubbo \& Gillespie (1940) in Australia had been pursuing an unknown growth factor for Clostridium acetobutylicum which was present in yeast concentrates. In the light of our prediction they tried $p$-aminobenzoic acid and found it highly active; this was announced in a letter to Nature published on 28 December 1940. They also succeeded in isolating a small amount of the benzoyl derivative of $p$-aminobenzoic acid from yeast; a year later Blanchard (1941) in the U.S.A. isolated the pure substance itself and in better yield. Since then it has been found to be essential for the growth of a wide variety of bacteria and other micro-organisms embracing many families and genera and including induced or biochemical mutants of both moulds and bacteria. I shall not bore you with a list-there must be quite fifty of them. Organisms which do not require it as a growth factor have been shown to synthesize it for themselves since extracts promote the growth of organisms which do require an exogenous source. $p$-Aminobenzoic acid has been proved therefore to be of natural occurrence and to be an essential metabolite in the full sense of the term.

$p$-Aminobenzoic acid has also been reported as having a number of biological effects or vitamin-like activities with the so-called higher forms of life. It was said to be a growth factor for the chick and to increase fertility and lactation in rats. Probably some of these effects may be explained by its conversion to folic acid (see later) by microbes in the gut. There was a number of papers, not always with agreeing results, suggesting that it restored hair colour both in experimental animals and man. One worker (Sieve, 1941) took fifty hospital patients at random ranging in age from 21 to 55 years with greying hair and observed, after 2 months' feeding with $p$-aminobenzoic acid, marked darkening in all cases. Possibly as a result of such work my vitamin was finally featured in a fashion magazine for ladies.

A number of other workers besides myself investigated the general applicability of the relationship between $p$-aminobenzoic acid and sulphonamides and found it to 
hold with virtually every combination of different sulphonamide and different organism tested. This again provides general support for the hypothesis, since from other experience one would expect an essential metabolite to have metabolic importance in all micro-organisms.

One point had been puzzling from the outset. Sulphonamides which are intrinsically more active than sulphanilamide itself (such as sulphathiazole, Fig. 1) appear to be chemically less like the metabolite than is sulphanilamide. However, satisfactory physico-chemical explanations for this have come from the work of Bell \& Roblin (1942) and others. It appears that the introduction of a weakly basic

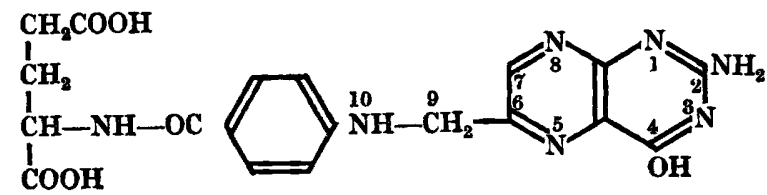

(a)

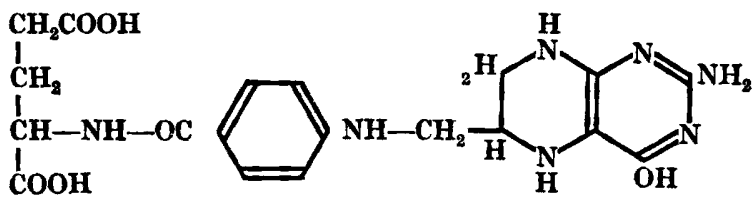

(b)

Fig. 6. (a) Folic acid (pteroylglutamic acid) and (b) tetrahydrofolic acid (tetrahydropteroylglutamic acid).

substituent into the $-\mathrm{SO}_{2} \mathrm{NH}_{2}$ group renders the electrical properties of the modified group $\left(-\mathrm{SO}_{2} \mathrm{NHR}\right)$, as judged by ionization and dissociation, even more nearly akin to the properties of the carboxylic acid group of $p$-aminobenzoic acid.

The hypothesis also predicted that sulphonamides inhibited the further utilization of $p$-aminobenzoic acid by the organism. What then is the nature of this reaction (Fig. 5) and especially of its product, which, if the theory is correct, must be of equal importance to the organism? Work during the war years in the U.S.A. on unknown vitamins or growth factors for birds, monkeys and several bacteria led to the realization that these factors were the same or similar. It culminated in the isolation, degradation and synthesis of the factor for Lactobacillus casei by the workers at Lederle Laboratories (Angier et al. 1946). This factor, called folic acid (Fig. 6), because it was first studied in extracts of spinach leaves, has a central $p$-aminobenzoic acid residue, linked through its carboxylic group to glutamic acid and through its amino group and a methylene bridge to a pteridine ring structure. (The pteridines had first been deseribed as of natural importance in the pigments of butterfly wings by Gowland Hopkins.) There has turned out to be a whole family of folic acids with different activities for different test organisms, but all contain the $p$-aminobenzoic acid and pteridine residues. To cut a long story short, it has now become clear that the substance with ultimate biological activity in the cell (as a 
coenzyme) is a derivative with a reduced (tetrahydro) pteridine ring (Fig. 6) and probably with two further glutamic acid residues in $\gamma$ peptide linkage with the first glutamic acid and with one another.

The cellular function of folic acid both in bacteria and higher forms is as a coenzyme in enzyme systems for the transport of units containing a single carbon atom from one molecule to another (see, for example, the review by Rabinowitz, 1960). It can do this with the carbon atom at either of two oxidation levels, that is either formyl (- $\mathrm{CHO})$ or hydroxymethyl $\left(-\mathrm{CH}_{2} \mathrm{OH}\right)$. The one-carbon residue released from the

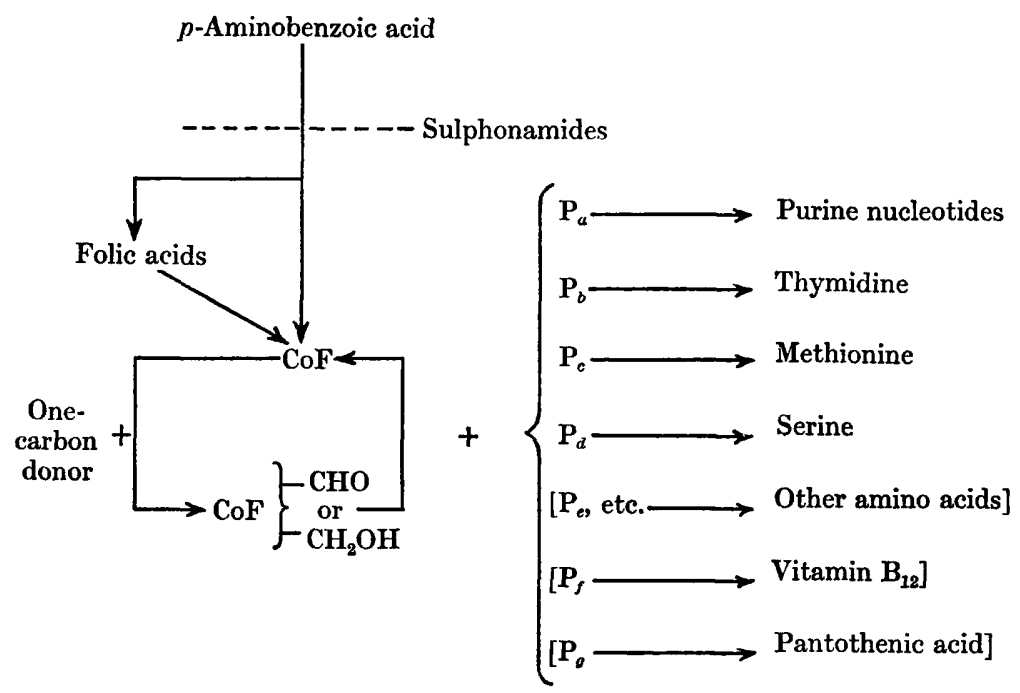

Fig. 7. Diagram summarizing the cellular functions of $p$-aminobenzoic acid and folic acid. CoF is the coenzyme form of folic acid; $P_{a}$ etc., are precursors of ultimate products. [ ], reaction indicated in only one or a few organisms. (From Woods \& Tucker, 1956.)

donor becomes combined with the $N^{10}$ atom (of the $p$-aminobenzoic acid residue) or forms a ring between the $N^{10}$ and the $N^{5}$ (Fig. 6). This compound reacts with an acceptor and transfers the one-carbon residue to it (Fig. 7).

Such one-carbon transfer reactions are essential steps in the synthesis of several amino acids, purines and thymine (the pyrimidine unique to DNA); the situation is summarized schematically in Fig. 7). Since inhibition of the metabolism of $p$ aminobenzoic acid creates a shortage of the folic acid coenzyme and thus in turn of essential constituents of both protein and nucleic acid, it is easy to see why sulphonamides have such a drastic effect on growth. Sulphonamide inhibition can also be overcome by appropriate mixtures of amino acids, purines and thymine; one is then adding preformed the ultimate products of the inhibited reaction. Such observations have indeed provided key clues for the elucidation of the function of folic acid.

There is now ample and convincing evidence that sulphonamides do in fact inhibit the conversion of $p$-aminobenzoic acid to folic acid. However, the precise biochemical mechanism of this conversion and the nature of the intermediates is not yet known with certainty, though there is recent progress suggesting that the folic acids with the reduced pteridine nucleus are formed directly. It must be confessed, 
however, that after 21 years I still cannot tell you the exact nature of the enzyme reaction which has $p$-aminobenzoic acid as substrate and is inhibited by sulphonamides. This I think is the only notable gap now in the story.*

If utilization for the synthesis of folic acid is the main or sole cellular function of $p$-aminobenzoic acid, the original hypothesis would demand two things. First, folic acid should also overcome sulphonamide inhibition. Secondly, it should do so irrespective of the concentration of sulphonamide; the relation should not in this case be a competitive one. This would be expected because folic acid would be the product of the blocked reaction and beyond the point of attack of sulphonamides; provided sufficient folic acid were given for the minimum needs of the organism (and provided it can get into the organism) growth should occur irrespective of sulphonamide concentration. These expectations have been fulfilled with a number of organisms tested. I will quote one example only from our own post-war work (Woods, 1954); this concerns the anaerobe Clostridium tetanomorphum which requires $p$-aminobenzoic acid for growth. There is the usual straight line competitive relation between $p$-aminobenzoic acid and sulphanilamide over a 1000 -fold range (Fig. 8). Folic acid (two forms were tested) was slightly more active than $p$-aminobenzoic acid in supporting growth in the absence of sulphonamide. However, once this amount of folic acid was present it was sufficient to support growth with any concentration of sulphanilamide (Fig. 8).

But with other bacteria folic acid, in the forms so far tested, is without effect either in replacing $p$-aminobenzoic acid or overcoming sulphonamide inhibition. Such organisms may be impermeable to folic acid (though this is unlikely) or unable to convert the form supplied to what we now believe to be the ultimate coenzyme form. The organisms which do not respond to folic acid include all those normally attacked by sulphonamide therapy in man. Whatever the reason for it this inactivity of folic acid may be of critical importance in explaining the therapeutic success of the sulphonamides.

Sulphonamides, like all other chemotherapeutic agents, are only successful because they are selectively toxic to the microbe and relatively harmless to the host. Any theory of sulphonamide action must explain this. How far can we go on the basis of our original hypothesis and the later work which I have described and which confirms it? I think the basis of a reasonable explanation is there.

Folic acid is an essential nutrient or vitamin for the animal and must be provided preformed in the diet. It follows therefore that animal cells cannot synthesize it. The metabolic lesion induced in sensitive bacteria by sulphonamides already exists in animals, and sulphonamides therefore can have no effect on them. It is of importance in this connexion that bacteria which require preformed folic acid for growth are also totally insensitive to sulphonamides. One must ask, however, why the folic acid present in host tissues does not overcome the action of the sulphonamides on the bacteria. I have already indicated that forms of folic acid so far tried, which include the forms in which it appears to occur free in animal tissues, are ineffective

* This gap has now been filled. Since this lecture was delivered Brown (1962) has shown that sulphathiazole and other sulphonamides inhibit competitively the activity of cell-free extracts of Escherichia coli catalysing the condensation of $p$-aminobenzoic acid with 2-amino-4-hydroxy-6hydroxymethyldihydropteridine to form dihydropteroic acid; the product is further transformed to tetrahydropteroylglutamic acid (Fig. 6). 
with many organisms including those which can be attacked by sulphonamide therapy. It is possible that the ultimate functional coenzyme form of folic acid only exists in cells firmly bound to or combined with the enzymes of which it is a part.

The idea that drugs might act by competing with substrates of enzyme systems was clearly not a new one and did not emerge as a result of the present work. However, the successful explanation of the action of a major group of chemotherapeutic agents along these lines certainly appeared to stimulate a lot of thought and experi-

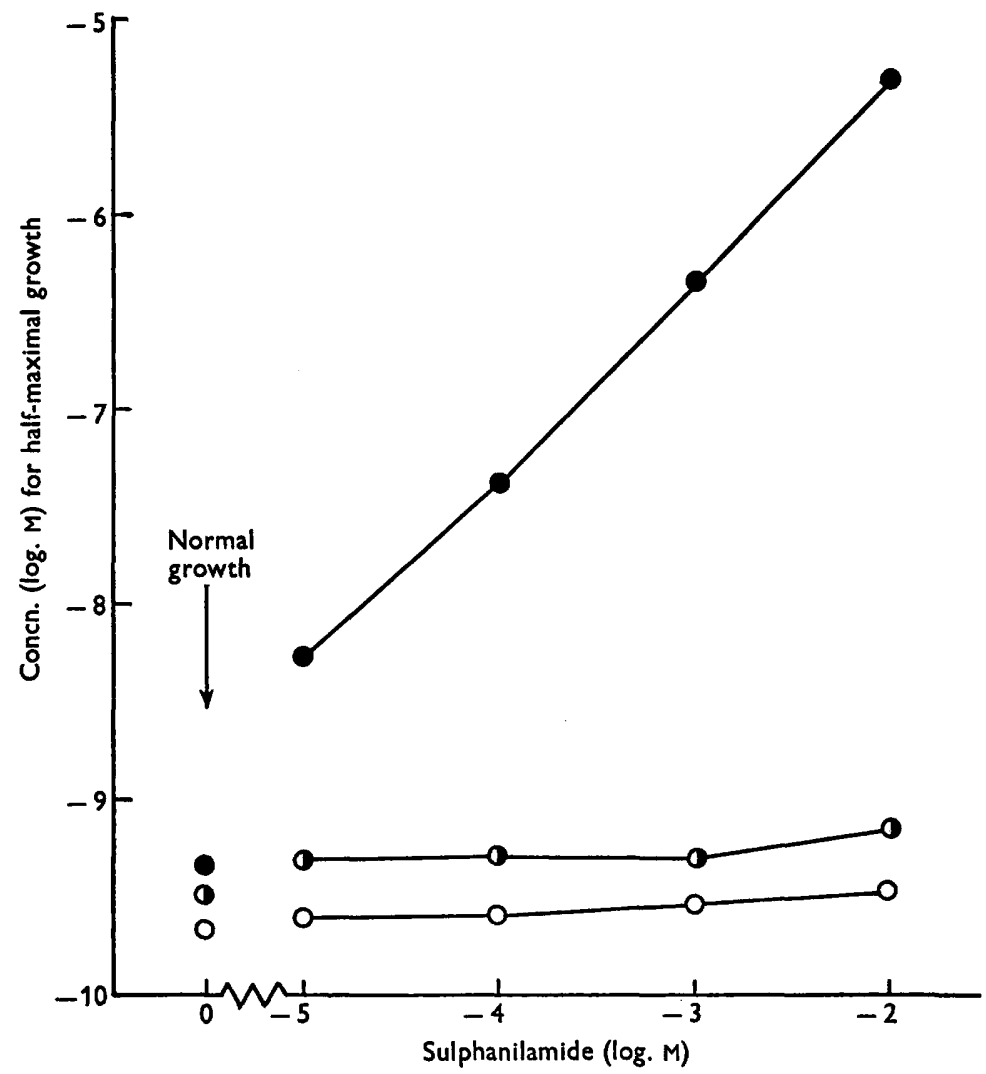

Fig. 8. The requirement of Clostridium tetanomorphum for $p$-aminobenzoic acid or folic acid for growth in the presence of varying concentrations of sulphanilamide. $p$-Aminobenzoic acid, - ; pteroylglutamic acid, - - - $N^{5}$-formyltetrahydropteroylglutamic acid (leucovorin), - - Data from unpublished experiments of Woods \& Ballio. (From Woods, 1954.)

ment. Vast numbers of analogues of other essential metabolites were synthesized and examined both for antibacterial and anti-cancer activity. A great many substances with antibacterial activity emerged and some have been very useful tools in metabolic studies as specific inhibitors. I do not think that any really successful therapeutic agent of the calibre of the sulphonamides has emerged.

Finally, I should like again to emphasize how much the outcome of this work owes to my own two teachers Dr Marjory Stephenson and Sir Paul Fildes. Of both of them it may truly be said, and with some appropriateness, that 'infection, not instruction, is the secret of education'. 


\section{REFERENCES}

A complete bibliography is not intended, since for some parts of the lecture this would require several hundred references.

Angier, R. B., Boothe, J. H., Hutchings, B. L., Mowat, J. H., Semb, J., Storstad, E. L. R., SubbaRow, Y., Waller, C. W., Cosulich, D. B., Fahrenbach, M. J., Hultquist, M. E., Kuh, E., Northey, E. H., Seeger, D. R., Sickels, J. P. \& Smith, J. M. (1946). The structure and synthesis of the liver L. casei factor. Science, 103, 667.

Bell, P. H. \& Robuin, R. O. (1942). Studies in chemotherapy. VII. A theory of the relation of structure to activity of sulfanilamide compounds. J. Amer. chem. Soc. 64, 2905.

Blanchard, K. C. (1941). The isolation of $p$-aminobenzoic acid from yeast. J. biol. Chem. $140,919$.

Brown, G. M. (1962). The biosynthesis of folic acid. II. Inhibition by sulfonamides. $J$. biol. Chem. 237, 536.

Domagk, G. (1935). Ein Beitrag zur Chemotherapie der bakteriellen Infektionen. Dtsch. med. Wschr. 61, 250.

Ehrlich, P. (1885). Das Sauerstoff-Bedürfniss des Organismus. Berlin: Hirschwald. [Reprinted with a translation into English in The Collected Papers of Paul Fhrlich, 1, 364 (1956). Ed. by F. Himmelweit. London: Pergamon Press.]

Fuller, A. T. (1937). Is $p$-aminobenzenesulphonamide the active agent in prontosil therapy? Lancet, i, 194.

GreEN, N. H. (1940). The mode of action of sulphanilamide. With special reference to a bacterial growth-stimulating factor (' $P$ ' factor) obtained from $\mathrm{Br}$. abortus and other bacteria. Brit. J. exp. Path. $21,38$.

McIntosh, J. \& WhitBy, L. E. H. (1939). The mode of action of drugs of the sulphonamide group. Lancet, $\mathrm{i}, 481$.

QuAstel, J. H. \& Wooldridge, W. R. (1928). Some properties of the dehydrogenating enzymes of bacteria. Biochem. J. 22, 689 .

Rabinowitz, J. C. (1960). Folic acid. In The Enzymes, 2, 185, 2nd edition. Ed. P. D. Boyer, H. Lardy and K. Myrbäck. New York: Academic Press Inc.

Rubbo, S. D. \& Gillespie, J. M. (1940). Para-aminobenzoic acid as a bacterial growth factor. Nature, Lond. 146, 838.

Sieve, B. F. (1941). Clinical achromotrichia. Science, 94, 257.

STAMP, T. C. (1939). Bacteriostatic action of sulphanilamide in vitro. Lancet, ii, 10.

TréfouëL, J., TréfouëL, J., Nitti, F. \& Bovet, D. (1935). Activité du $p$-aminophénylsulfamide sur les infections streptococciques expérimentales de la souris et du lapin. C.R. Soc. Biol., Paris, 120, 756.

Woods, D. D. (1940). The relation of $p$-aminobenzoic acid to the mechanism of the action of sulphanilamide. Brit. J. exp. Path. 21, 74.

Woods, D. D. (1954). Metabolic relations between $p$-aminobenzoic acid and folic acid in micro-organisms. In Chemistry and Biology of Pteridines, p. 220. Ed. G. E. W. Wolstenholme and M. P. Cameron. London: Churchill.

Woods, D. D. \& Findes, P. (1940). The anti-sulphanilamide activity (in vitro) of $p$ aminobenzoic acid and related compounds. Chem. \& Ind. 18, 133.

Woops, D. D. \& Tucker, R. G. (1958). The relation of strategy to tactics: some general biochemical principles. Symp. Soc. gen. Microbiol. 8, 1.

\section{EXPLANATION OF PLATE 1}

Fig. 1. Reconstruction of an early experiment showing antagonism by $p$-aminobenzoic acid of inhibition of growth by sulphanilamide. 1, Control; 2 , + sulphanilamide; 3 and 4, + sulphanilamide and $p$-aminobenzoic acid; $5,+p$-aminobenzoic acid only.

Fig. 2. Molecular models of $p$-aminobenzoic acid (left) and sulphanilamide (right). 


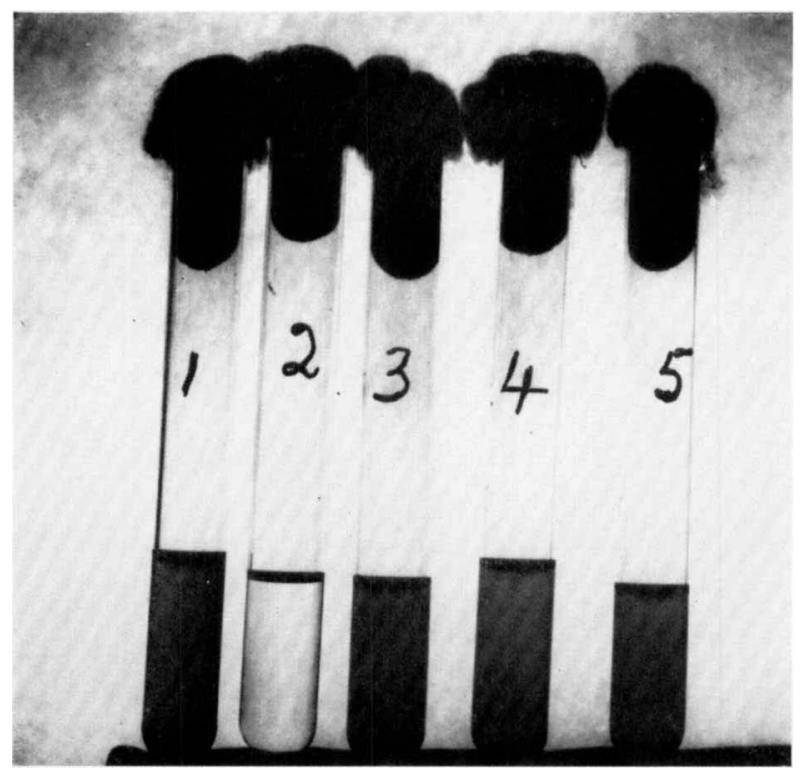

Fig. 1

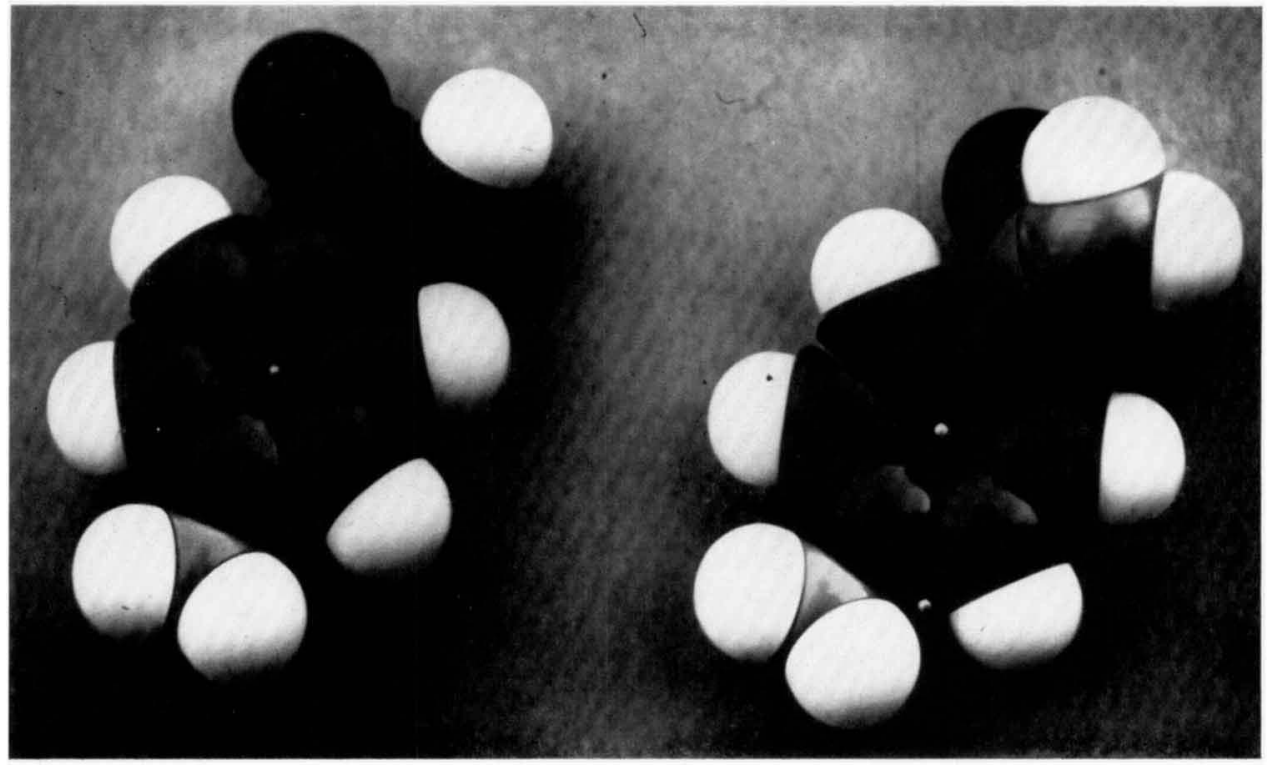

Fig. 2 